\title{
Distribution of the $\mathrm{Ca}$ (Oxford) antigen in lung neoplasms and non-neoplastic lung tissues
}

\author{
FJ PARADINAS, G BOXER, KD BAGSHAWE* \\ From the Departments of Histopathology and Experimental Pathology, and *Medical Oncology, Charing \\ Cross Hospital Medical School, London W6 8RF
}

SUMMARY The Ca (Oxford) antigen was originally isolated from a malignant neoplasm and with few exceptions was reported to discriminate between malignant and non-malignant neoplasms or normal tissues. Using the $\mathrm{Ca} 1$ antibody we have studied the Ca distribution in 54 lung neoplasms and adjacent non-neoplastic lung tissue. Staining of tumours was very focal and the proportion of positive cells varied from about $50 \%$ for adenocarcinomas to less than $1 \%$ for oat cell carcinomas, which were often negative. Focal cytoplasmic staining can be seen in all neoplasms, whereas membrane staining is mainly seen in their areas of glandular and squamous differentiation. We found consistently strong membrane staining of alveolar type II pneumocytes in non-neoplastic lung. This staining may be useful in differentiating type II cells from alveolar macrophages which only occasionally showed granular cytoplasmic staining, probably due to phagocytosed $\mathrm{Ca}$. Mucin from tumours and bronchi did not stain but there was consistent staining of alveolar serous exudate suggesting extracellular location of $\mathrm{Ca}$.

The $\mathrm{Ca}$ antigen consists of two glycoproteins with high carbohydrate content and molecular weights of 350000 and 390000 . It was isolated by Ashall, Bramwell and Harris ${ }^{1}$ from cell membrane preparations of a human laryngeal squamous carcinoma and it has been claimed that it has a high degree of specificity for malignant neoplastic cells; being present in most malignant neoplasms tested with the specific Ca 1 monoclonal antibody and absent from benign neoplasms and normal tissues except urothelium and Fallopian tube epithelium. ${ }^{2}$

We have studied the distribution of the $\mathrm{Ca}$ antigen in neoplastic and non-neoplastic lung and report its presence in non-neoplastic type II pneumocytes and in variable amounts in malignant neoplasms, ranging from $100 \%$ of cells in some bronchioalveolar tumours to less than $1 \%$ in carcinoids and oat cell carcinomas.

\section{Material and methods}

TISSUES

$\mathrm{Ca}$ antigenicity withstands formalin fixation. ${ }^{2}$ Accordingly all our material was fixed in $10 \%$ neutral formalin and processed to paraffin wax. Of the 54 tumours examined 51 were from lobectomy or

Accepted for publication 1 August 1983 pneumonectomy specimens and fixation included expansion of the air spaces with formalin at a pressure of $25 \mathrm{~mm}$. Two specimens of oat cell carcinoma and one of bronchioalveolar carcinoma were biopsies. Between one and three slides per case were examined. These included between 0.05 and $5 \mathrm{~cm}^{2}$ of tumour (mean $2 \mathrm{~cm}^{2}$ per case) and 0.01 to $3 \mathrm{~cm}^{2}$ of non neoplastic lung (mean $1 \mathrm{~cm}^{2}$ per case). The tumour types and numbers examined of each type are shown in Table 1 . The non-neoplastic tissues included foci of lipid pneumonia in three cases, interstitial inflammation and fibrosis with alveolar macrophages in 43 cases, collapse in eight cases, bronchopneumonia in one case and hyperplastic hilar lymph nodes in five cases. A block including partly normal and partly bronchiectatic lung served as further non-neoplastic control.

\section{REAGENTS}

The RP 82-Ca 1 (an IgM mouse monoclonal antibody) was kindly donated by Wellcome Diagnostics. It is supplied in freeze-dried vials, dissolved in $0.5 \mathrm{ml}$ of distilled water and a further $0.5 \mathrm{ml}$ of phosphate buffer solution (PBS) before use. The solution contains $25 \mu \mathrm{g} / \mathrm{ml}$ of Ca 1 .

Endogenous peroxidase was blocked with 1/10 dilution of $30 \%$ hydrogen peroxide $(\mathrm{BDH})$ and trypsinisation carried out with a buffered solution of 
Table 1 Tumour types and number of cases showing cytoplasmic and membrane (in parentheses) staining as well as mean percentage of cell staining for each tumour type (right hand column)

\begin{tabular}{|c|c|c|c|c|c|}
\hline \multirow[t]{2}{*}{ Tumour type } & \multirow{2}{*}{$\begin{array}{l}\text { Total No of } \\
\text { cases }\end{array}$} & \multicolumn{3}{|c|}{ Proportion of cells stained } & \multirow[t]{2}{*}{ Mean $\%$ of cells stained } \\
\hline & & $\begin{array}{l}>20 \% \\
\text { No Cases }\end{array}$ & $\begin{array}{l}1-20 \\
\text { No Cases }\end{array}$ & $\begin{array}{l}<1 \text { or } 0 \\
\text { No Cases }\end{array}$ & \\
\hline $\begin{array}{l}\text { Large cell undifferentiated } \\
\text { Squamous } \\
\text { Small cell undifferentiated } \\
\text { Carcinoid } \\
\text { Papillary and bronchioalveolar adenocarcinoma } \\
\text { Acinar adenocarcinoma } \\
\text { Goblet cell adenocarcinoma } \\
\text { Totals }\end{array}$ & $\begin{array}{r}13 \\
12 \\
7 \\
7 \\
7 \\
6 \\
2 \\
2\end{array}$ & $\begin{array}{c}2(0) \\
3(2) \\
0(0) \\
0(0) \\
1(6) \\
5(4) \\
0(0) \\
11(12)\end{array}$ & $\begin{array}{l}9(8) \\
9(9) \\
1(0) \\
0(1) \\
6(1) \\
1(2) \\
2(2) \\
28(23)\end{array}$ & $\begin{array}{c}2(5) \\
0(1) \\
6(7) \\
7(6) \\
0(0) \\
0(0) \\
0(0) \\
15(19)\end{array}$ & $\begin{array}{c}10 \%(4 \%) \\
15 \%(9 \%) \\
1 \%(0) \\
0 \cdot 5 \%(0 \cdot 1 \%) \\
18 \%(47 \%) \\
47 \%(43 \%) \\
1 \%(3 \%) \\
13 \%(15 \%)\end{array}$ \\
\hline
\end{tabular}

trypsin (Sigma, type IX). Peroxidase-labelled rabbit antimouse immunoglobulin (Dako $P, 161$ ) was used. Diaminobenzidine was used as a substrate.

\section{METHOD}

A standard indirect immunoperoxidase method in a moist chamber was done including trypsinisation in an incubator at $37^{\circ}$ for $30 \mathrm{~min}$, incubation with $\mathrm{Ca} 1$ solution at room temperature for $60 \mathrm{~min}$, incubation with conjugate solution at room temperature for 30 min and incubation with substrate solution at room temperature for $5 \mathrm{~min}$.

\section{CONTROLS}

For each test section a negative control using the adjacent section and omitting the $\mathrm{Ca} 1$ antibody was prepared. The possibility of non-specific IgM binding was tested and controls were done in every other case using IgM monoclonal antiserum against thymocytes of $\mathrm{CBA} / \mathrm{J}$ mice (Miles Laboratories). Further non-specific IgM binding was tested in one adenocarcinoma and in bronchiectatic lung with IgM antiserum against a bacterial antigen (Wellcome Diagnostics) and with nine culture supernatants known to contain monoclonal IgM with the following specificities: CEA (five), early placental antigens (three) and ovarian carcinoma antigen (one). Endogenous peroxidase blocking controls and controls in which trypsinisation was omitted were included with each batch.

\section{Results}

\section{CONTROLS}

Some staining of cartilage and collagen was seen with the nine IgM monoclonals in which culture fluid rather than affinity purified antibody was used. Similar staining was observed with culture fluid alone which was thought to be the source of the nonspecific staining. No such staining was seen with the anti-thymocyte and anti-bacterial antigen IgM. Specific staining of bronchial epithelium and mac- rophages was seen with the five anti-CEA IgM monoclonals. Other cells and tissues were negative in all controls. There was no unspecific IgM binding ${ }^{2}$ and trypsinisation made no difference to the results of $\mathrm{Ca} 1$ staining.

\section{Ca 1 STAINING OF NEOPLASMS}

Staining of neoplastic cells was either cytoplasmic (Fig. 1) seen in groups of tumour cells in a haphazard distribution in all tumour types, or surface stain-

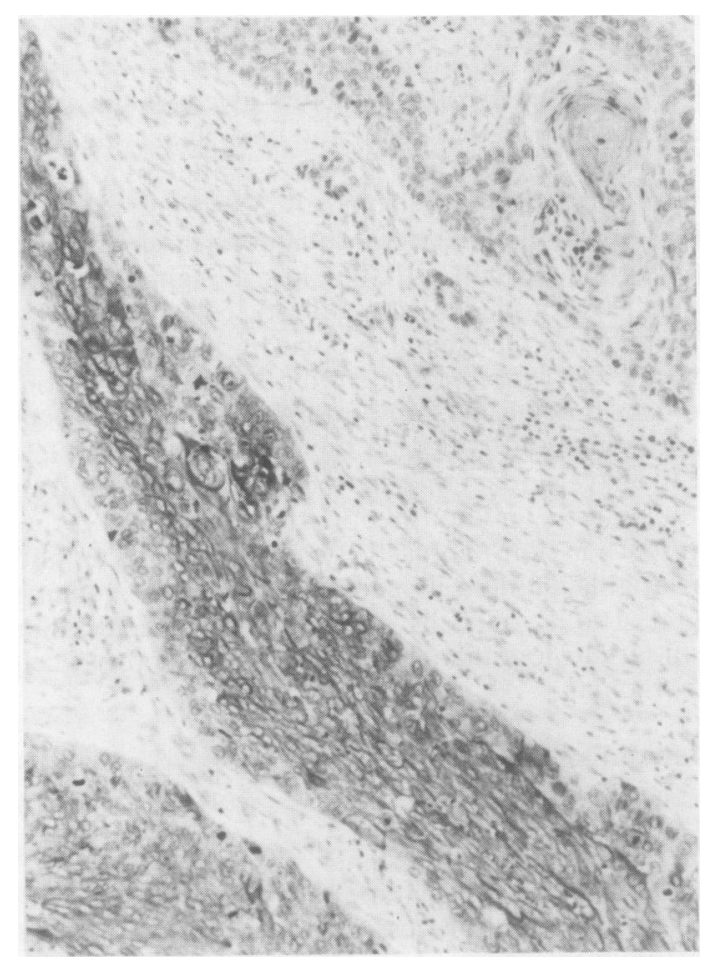

Fig. 1 Focal cytoplasmic staining of squamous carcinoma of the bronchus (left lower corner). Immunoperoxidase $\times$ 90. 


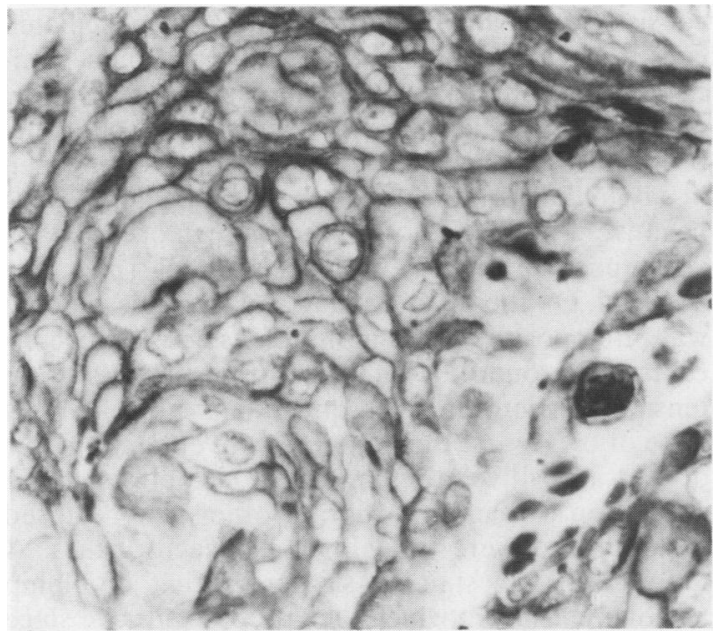

Fig. 2 Strong surfače ("intercellular") staining and weak cytoplasmic staining of squamous carcinoma.

Immunoperoxidase $\times 375$.

ing; the latter being variable depending on the tumour type but featuring three main patterns: "intercellular" staining in keratinising areas of squamous cell carcinomas (Fig. 2), "surface" staining, seen particularly in papillary and bronchioalveolar carcinomas (Fig. 3) and "luminal" staining seen in acinar adenocarcinomas (Fig. 4) but also in vacuoles containing PAS-positive diastase-resistant

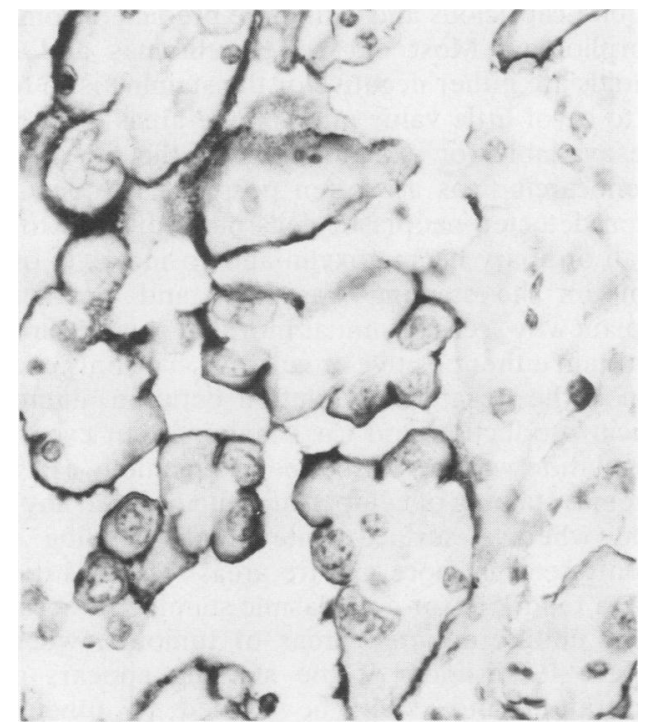

Fig. 3 Surface staining in papillary adenocarcinoma. Cell membrane staining is usually restricted to the surface of tumour clusters and less common between the cells in each cluster. Immunoperoxidase $\times 375$.

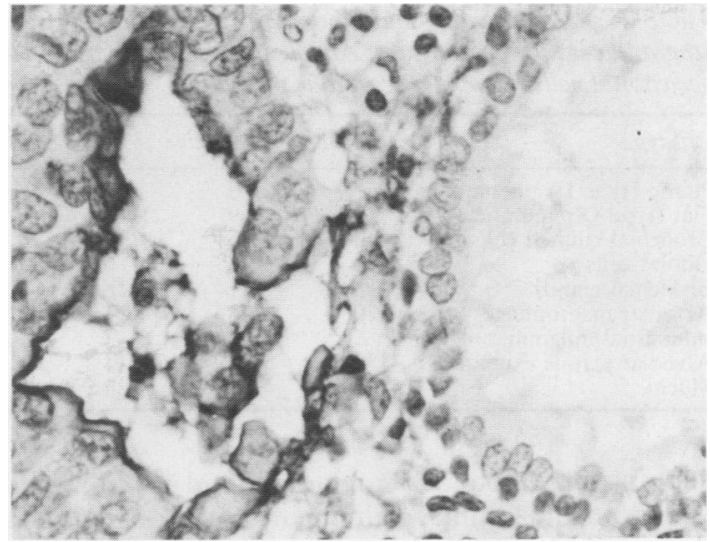

Fig. 4 Strong luminal surface staining of acinar adenocarcinoma (left) adjacent to a small bronchus (right) which shows no staining. Immunoperoxidase $\times 375$.

material in large cell anaplastic carcinomas and some squamous carcinomas. Often, cytoplasmic and surface staining coexisted in the same cell. The relative frequency and extent of cytoplasmic and surface staining in all tumour types is seen in Table 1. Necrotic tumour was occasionally positive when the adjacent viable tumour was positive. Squamous carcinoma in situ in bronchial mucosa was present in four cases. This showed cytoplasmic and "intercellular" staining in three cases and was negative in one case.

Staining of all the tumour examined was only seen in two adenocarcinomas but even in adenocarcinomas as a group the $\mathrm{Ca} 1$ antibody stained on average less than half of the tumour (Table 1). The pattern of adenocarcinomas seems to correlate with the distribution of the staining; most acinar adenocarcinomas had extensive cytoplasmic as well as luminal staining, whereas most bronchioalveolar and papillary adenocarcinomas showed either negative or weak cytoplasmic staining but strong surface staining (Fig. 3). Carcinomas with abundant goblet cells and areas of heavy mucin production in other adenocarcinomas were in most areas negative although a few positive cells were found in each case in non-mucin containing cells.

Squamous carcinoma stained only focally (Fig. 1); cytoplasmic staining was seen mainly in poorly differentiated areas, whereas areas with prickle cells and keratin often stained also the cell surface ("interstitial" pattern Fig. 2). Some large cell undifferentiated carcinomas showed very focal cytoplasmic staining and luminal staining of ill-formed acini suggesting a glandular differentiation. In contrast most oat-cell carcinomas and carcinoids were negative; the exception being very focal cytoplasmic 
Table 2 Frequency of staining of non-neoplastic cells in lung adjacent to the tumours. Any staining, even that of occasional cells, has been scored as positive

\begin{tabular}{lccc}
\hline Cell type & Positive & Negative & Not present \\
\hline Plump (type II) pneumocytes & 51 & 0 & 3 \\
Flat (type I) pneumocytes & 42 & 9 & 3 \\
Bronchial ciliated cells & 43 & 5 & 6 \\
Goblet cells & 0 & 48 & 6 \\
Bronchial glands & 15 & 11 & 28 \\
Alveolar macrophages & 20 & 23 & 11 \\
Interstitial inflammatory cells & 1 & 50 & 3 \\
Alveolar serous exudate & 32 & 8 & 14 \\
Mucin & 3 & 27 & 24 \\
\hline
\end{tabular}

staining of two oat cell carcinomas and a spindle cell carcinoid and luminal staining in a focus of glandular differentiation in another carcinoid.

\section{Ca 1 STAINING OF NON-NEOPLASTIC TISSUES}

The results are shown in Table 2; surface staining, often coexisting with cytoplasmic staining, was seen in all cases in plump alveolar cells morphologically consistent with type II pneumocytes and particularly numerous in areas of repair or fibrosis at the periphery of tumours (Fig. 5). In areas where plump cells were numerous intervening flat cells morphologically consistent with type I pneumocytes also stained, but in areas of normal lung the latter were

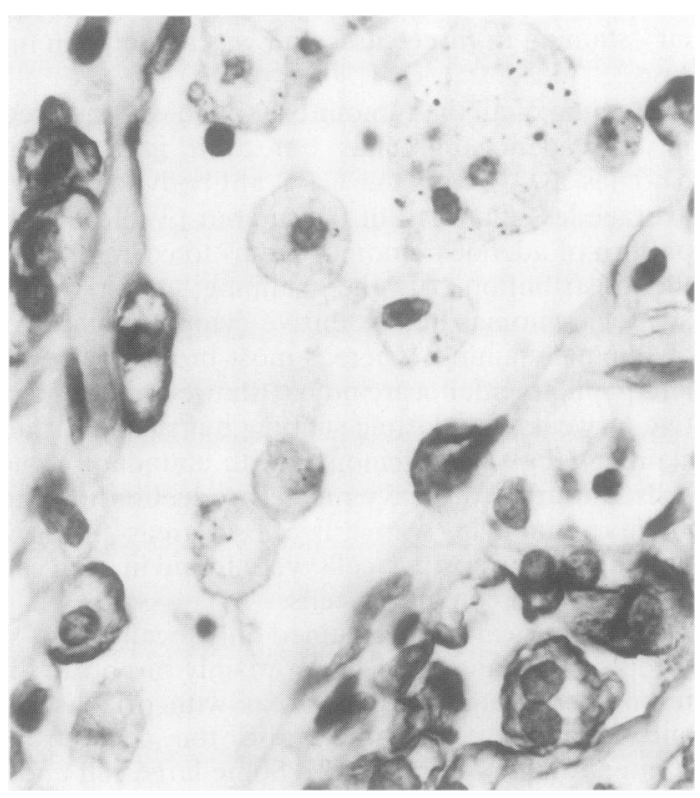

Fig. 5 Strong surface staining of type II alveolar cells which show also variable but weaker cytoplasmic staining. Alveolar macrophages contain carbon (black) and occasional positive cytoplasmic granules, presumably phagocytosed material. Immunoperoxidase $\times 600$. consistently negative. Very often, occasional ciliated cells from bronchi had a little staining of their luminal surface but goblet cells appeared consistently negative. A little luminal staining of occasional bronchial glands (particularly ductal cells) was seen in about half of the cases, but most glands were negative. Mucin did not stain, although occasionally a few positive threads were seen amongst negative material. On the other hand alveolar serous exudate was often positive, with more intense positivity concentrated around air-bubbles, suggesting a surface tension distribution. "Desquamated" alveolar cells were of two types: the majority were either negative or had a positive stippling of the cytoplasm; these cells often contained carbon or other phagocytosed material and were thought to be macrophages. A few had strong staining similar to that of plump alveolar cells from which they probably derive since these desquamated positive cells were more numerous in areas where plump cells were also numerous. Macrophages in interstitial tissues and all other types of inflammatory cells in the lung and lymph nodes were negative.

\section{Discussion}

Our results show considerable variation in the intensity and pattern of staining in different lung tumours. Cytoplasmic staining is seen focally in all carcinomas, particularly in less well differentiated areas, but positive or negative cytoplasmic staining is quite capricious and cannot be predicted from the morphology. Most oat cell carcinomas and carcinoids are either negative or the staining is so focal as to be of little value unless large areas of tumour are available for examination; on the other hand adenocarcinomas are often positive and the $\mathrm{Ca} 1$ often detected neoplastic cells more difficult to see in an ordinary haematoxylin and eosin. As in other tumours the staining was focal and we cannot explain why areas of similar morphology in a tumour can stain either positive or negative. The only exception is the negative correlation between abundant mucin production and $\mathrm{Ca} 1$ staining, but even this correlation was not absolute. In squamous cell carcinomas staining of cytoplasm could occur in any cell type whereas surface (interstitial) staining was mainly seen in more mature areas. There is therefore a tendency for cytoplasmic staining to occur in more undifferentiated areas of tumours, whereas surface localisation of the staining appears with maturation and could be related to functional changes in the cell membrane.

It is clear that the $\mathrm{Ca}$ antigen is not exclusive to malignancy and a more extensive examination of normal and neoplastic tissues than that in the orig- 
inal description ${ }^{12}$ has increased the range of known non-neoplastic cell types which consistently react with the $\mathrm{Ca} 1$ antibody. ${ }^{3-7}$ Our observation that normal and regenerating cells thought to be type II alveolar pneumocytes consistently stain, has been confirmed by others ${ }^{78}$ and is of interest, since this cell type is thought to be more primitive, actively dividing after alveolar damage, and the cell from which alveolar type I pneumocytes eventually derive. ${ }^{9}$ Further study of what these cells and neoplastic cells which express the $\mathrm{Ca}$ antigen have in common, may provide a clue to the functional significance of this antigen. In any case the $\mathrm{Ca} 1$ antibody differentiates clearly between desquamated alveolar epithelium and alveolar macrophages and may be of use in the investigation of cell types in desquamative interstitial pneumonia and other conditions in which the nature of the intra-alveolar cell types has been controversial.

Staining of other non-neoplastic cells was sufficiently infrequent to be of little value, but it is of interest that all the positivity was in epithelial cells and that no cross-reaction with inflammatory cells was seen other than the positivity in the cytoplasm of macrophages attributable to phagocytosis and easy to distinguish from that in epithelial cells. In both the practical applications and the distribution in tissues, including the lung, the $\mathrm{Ca}$ antigen resembles the epithelial membrane antigen ${ }^{1012}$ from which it clearly differs in molecular weight. ${ }^{12}$

The positive staining of serous exudate in our material was consistent and strong and was not present in either IgM or other controls. It should not be dismissed as an artefact and suggests the possibility that some of the $\mathrm{Ca}$ antigen may be secreted or lost in areas of abundant production by neoplastic or non-neoplastic cells. Indeed, we occasionally observed positive staining of lymph or serum in the stroma of tumours. In this context the isolation of the antigen from urine by Bramwell et $a l^{13}$ and the finding of $\mathrm{Ca}$ reactivity in serum of patients with cancer (H Harris, personal communication, 1983) support the view that $\mathrm{Ca}$ may be present in extracellular fluids and opens up further possible applications of this antigen in the study of disease.

\section{References}

' Ashall F, Bramwell ME, Harris H. A new marker for human cancer cells. 1 . The $\mathrm{Ca}$ antigen and the $\mathrm{Ca} 1$ antibody. Lancet 1982;ii: $1-6$.

${ }^{2}$ McGee JO'D, Woods JC, Ashall F, Bramwell ME, Harris H. A new marker for human cancer cells. 2. Immunohistological detection of the $\mathrm{Ca}$ antigen in human tissues with the $\mathrm{Ca} 1$ antibody. Lancet 1982;ii:7-10.

${ }^{3}$ Woods JC, Spriggs AI, Harris H, McGee JO'D. A new marker for human cancer cells. 3. Immunocytochemical detection of malignant cells in serous fluids with the $\mathrm{Ca} 1$ antibody. Lancet 1982;ii:512-82.

4 Simpson HW, Candlish W, Liddle C, McGregor FM, Mutch F, Tinkler B. Experience of the Oxford tumour marker. Lancet 1983;i: 1097.

${ }^{5}$ Burnett RA, Deery ARS, Adamson MR, Liddle C, Thomas M, Roberts GH. Evaluation of $\mathrm{Ca} 1$ antibody in pleural biopsy material. Lancet 1983;i:1158.

${ }^{6}$ Beckford U, Chantler S, Dayan AD. Effects of various technical parameters on immunoperoxidase localization of $\mathrm{Ca}$ antigen in mammary tumours. Proceedings of the XXXIst Colloquium on protides of Biological Fluids. Brussels, 1983.

${ }^{7}$ Pallesen G, Loue Jepson F, Hastrup J, Ipsen A, Kvidberg N. Experience with the Oxford tumour marker ( $\mathrm{Ca} 1)$ in serous fluids. Lancet $1983 ; \mathrm{i}: 1326$.

${ }^{8}$ Heryet JC, Fleming KA, Czerniewski I, Turner ELT, McGee $J O^{\prime} D$. Detection of Ca 1 positive cells in normal and nonneoplastic tissue and in preinvasive and invasive cancer. Edinburgh: Proceedings of the Pathology Society of Great Britain and Ireland 1983;147:19.

9 Evans MJ, Cabral LJ, Stephens RJ, Freeman G. Transformation of alveolar type 2 cells to type 1 cells following exposure to $\mathrm{NO}_{2}$. Exp Mol Pathol 1975;22:142-50.

${ }^{10}$ Sloane JP, Ormerod MG, Imrie SF, Coombes RC. The use of antisera to epithelial membrane antigen in detecting micrometastases in histological sections. Br J Cancer 1980;42: 392-8.

" Dearnaley DP, Sloane JP, Ormerod MG, et al. Increased detection of mammary carcinoma cells in marrow smears using antisera to epithelial membrane antigen. $\mathrm{Br} J$ Cancer $1981 ; 44: 85-90$.

${ }^{12}$ Sloane JP, Ormerod MG. Distribution of epithelial membrane antigen in normal and neoplastic tissues and its value in diagnostic tumour pathology. Cancer 1981;47:1786-95.

${ }^{13}$ Bramwell ME, Bhavananolan VP, Wiseman G, Harris H. Structure and function of the $\mathrm{Ca}$ antigen. $\mathrm{Br} J$ Cancer 1983;48:177-83.

Requests for reprints to: Dr FJ Paradinas, Histopathology Department, Charing Cross Hospital Medical School, London W6 8RF, England. 